\title{
Geomagnetic Paleointensities for the Period 6,000 to 3,000 Years B.P. Determined from Lavas and Pyroclastic Flows in Japan
}

\author{
Hidefumi TANAKA \\ Department of Applied Physics, Tokyo Institute of Technology, \\ Meguro-ku, Tokyo, Japan
}

(Received June 12, 1982; Revised December 28, 1982)

\begin{abstract}
Paleointensity of the geomagnetic field was studied with precisely dated lava flows and pyroclastic flows in Japan older than 3,000 years B.P. by the Thellier's stepwise heating method. The errors inherent in the ages of the rocks were fully evaluated in this work. Samples collected from five lava flows and three pyroclastic flows provided successful results. Two examples were found indicating that the apparent linear NRM-TRM relation in the Arai diagram is probably due to the effect of TCRM produced during heat treatment. This phenomenon was detected by comparing the result with those from other specimens taken from the same flow and treated with the same procedure in the Thellier's experiment simultaneously with two samples mentioned above. This result strongly suggests that the Thellier's experiment should be done by using multiple at least three specimens. Japanese data including the present results are consistent to already proposed trend of secular variation in which geomagnetic field intensity gradually increased from about 6,000 years B.P. to 2,000 years B.P. and then gradually decreased to the present-day value. Secular variation of shorter periods also seems to exist superposed on that of a longer period.
\end{abstract}

\section{Introduction}

Importance of the study of the intensity of the past geomagnetic field (paleointensity) is well recognized, and many authors have reported paleointensity data as summarized by SMith (1967) and Burlatskaya and NaChasova (1977). However, amount of intensity data is still insufficient in comparison with the direction data mainly because of laborious experimental method to determine the paleointensity. Among several methods proposed, only those by THELLIER and THELLIER (1959) and SHAW (1974) can be taken as reliable. Shaw's method is relatively easy and still has a high reliability as KoNO (1978) fully examined, but probability of experimental success may be lower than in the Thellier's method because the former requires an initial heating of samples up to a high temperature of about $600^{\circ} \mathrm{C}$, which often causes changes in the magnetic characteristics of the samples by oxidation. Thellier's method was adopted throughout this study because it is at present the most reliable.

We noticed scarcity of paleointensity data especially in periods older than 3,000 years B.P. when we looked at the secular variation curve such as that summarized by BARTON $e t$ al. (1979), although numbers of intensity data have much increased in the last ten years (cf. 
Cox, 1969; Kono, 1972). The present study aims to provide several paleointensity data for ages older than 3,000 years ago. There are numerous young volcanos in Japan, and many of the volcanic flows have been dated by radiocarbon method. Recent development of tephrochronology has made it possible to correlate sequences of some of the volcanic rocks at different volcanoes which are geographically apart to each other (MACHIDA, 1976).

Samples were collected from some of precisely dated lava flows and pyroclastic flows mainly with ages between 3,000 and 6,000 years B.P. to cover the relative scarcity of paleointensity in this age range. Much caution was taken in assessing the ages of collected volcanic rocks. Single radiocarbon date sometimes contains large error, so geological or tephrochronological evidences were also sought to support the radiocarbon age.

\section{Samples}

Radiocarbon dates are usually reported with their errors which are determined statistically in the dating experiment (KIGOSHI, 1967). This error has little significance because errors by other factors such as chemical contamination of sample are usually much greater than the statistical one. In this study error in age was determined as follows; when only one radiocarbon date is available, the error is assumed to be ten percent of the age value. When more than one radiocarbon dates were determined from the same layer, the arithmetic mean and the standard deviation were used as the age and its error for the layer. The layer with no radiocarbon dates but having age limits deduced from the dated layers above and below it was also collected, and in this case, the age of the layer is the average of the two ages and the error is assumed to be the sum of half the time span of the two and ten percent of the two dates.

Some of the pyroclastic flows have very stable natural remanent magnetization (NRM) of thermal origin, so that such samples with reliable radiocarbon date were examined in this study. Pyroclastic flows with converged NRM directions were used in the paleointensity experiment because it means that the formation temperature was high enough to produce a thermo-remanent magnetization (TRM) in situ.

More than ten of lava flows and pyroclastic flows were sampled in the Central and the Western Japan. Among these samples five lava flows and three pyroclastic flows with converged NRM directions were selected. Sampling localities are shown in Fig. 1. Table 1 contains the age of each sample and its error which was determined based on the above criteria. The age determination of each lava flows and pyroclastic flows are described as follows.

One pyroclastic flow (HK 7) dated at 2,900 \pm 100 years B.P. by a carbonated wood contained in the flow and one lava flow (HK 1) having four radiocarbon dates with a mean of $4,475 \pm 349$ years B.P. (MACHIDA, 1977) were selected from Hakone Volcano about $80 \mathrm{~km}$ southwest of Tokyo.

One lava flow (FJ 6) was selected from Mt. Fuji near Hakone Volcano. This flow has no direct radiocarbon date. However, it is known from tephrochronological observations that it is stratigraphically lower than a pyroclastic flow having a radiocarbon date of 3,040 \pm 50 years B.P. (MACHIDA, 1977) and higher than the Fuji Black Pumice which was formed during the relatively quiet period of Mt. Fuji between 10,000 and 5,000 years B.P. (MACHIDA, 1964). Therefore, we can regard the age of this lava flow (FJ 6) as 4,000 $\pm 1,500$ years B.P. 


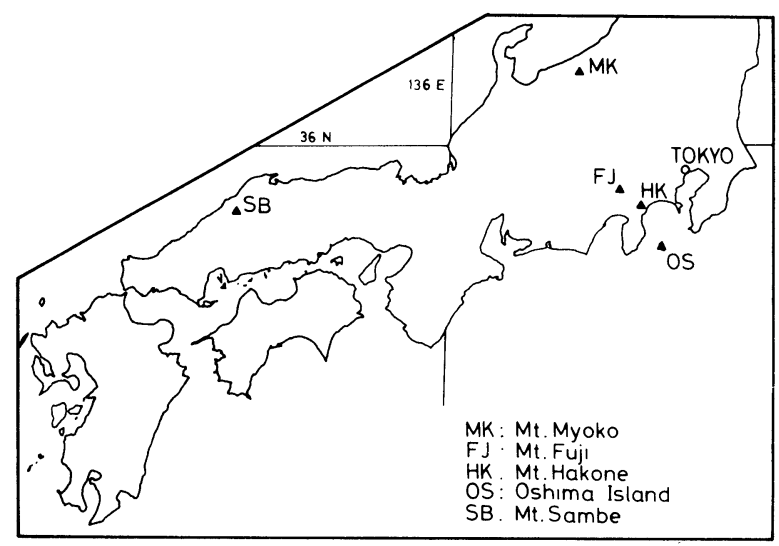

Fig. 1. Locations of five volcanos whose volcanic flows were taken for the paleointensity experiment.

In Oshima Island about $120 \mathrm{~km}$ south of Tokyo, samples were collected from two lava flows. One of them (OS 2) lies under the member $S_{2}$ of the Younger Oshima Group (NAKAMURA, 1964) which has four radiocarbon dates (IsSHIKI et al., 1981), and also lies above a layer which contains human remains. The mean age of $S_{2}$ is $1,410 \pm 83$ years B.P. and the human remains is inferred to be about 4,500 years B.P. old (IssHIKI, personal communication). This gives the age of the lava flow at 3,000 $\pm 1,500$ years B.P. Another lava (OS 3) is from the member $\mathrm{O}_{21}$ of the Older Oshima Group (TAZAwA, 1980) which has a radiocarbon date of 5,520 \pm 370 years B.P. (TAZAWA, 1981).

From Myoko Volcano, Central Japan, two pyroclastic flows were selected. One of them (MK 1) has radiocarbon date of 4,790 \pm 110 years B.P., and another (MK 2) has $5,880 \pm 190$ years B.P. These dates, each determined from only a single carbonated material, agree with the ages expected from geological and tephrochronological considerations (Hayatsu, 1975; Hayatsu and Furukawa, 1981).

The lava flow (SB 5) from Mt. Sambe, Western Japan, has no radiocarbon date, but is stratigraphically correlated between two black soil layers. These layers have radiocarbon dates of 3,680 \pm 90 years B.P. and 4,480 \pm 110 years B.P., respectively (MATSUI and INOUE, 1970 ), so that we can assign this lava an age of $4,000 \pm 800$ years B.P.

Table 1 summarizes NRM directions of eight flows which gave successful results in the paleointensity experiment. The data in this table were derived without any demagnetization. The direction of the NRM does not change significantly during the course of thermal demagnetization. NRM intensity of all samples were relatively large, ranging from 1 to $10 \mathrm{~A} / \mathrm{m}$, and that of each specimen used for paleointensity experiment is tabulated in Table 2 together with the experimental results.

\section{Paleointensity Experiment}

Experimental results are summarized in Table 2 and NRM-TRM diagrams are shown 


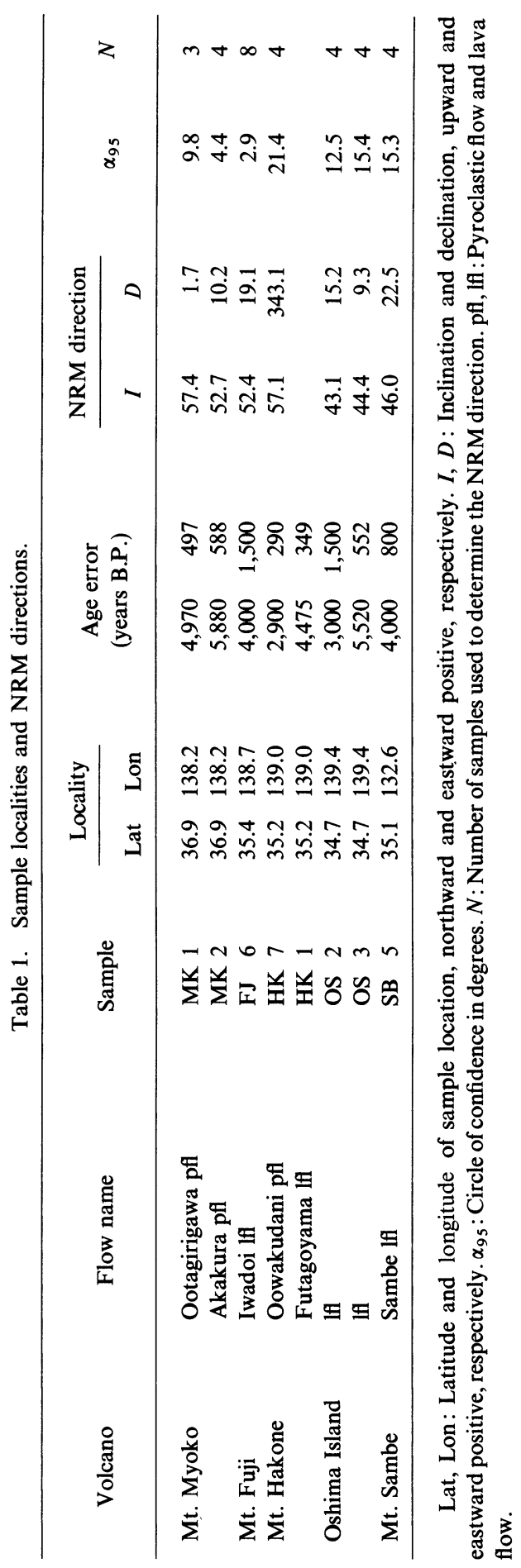


in Fig. 2-Fig. 9. An open circle in the diagram represents the point which is rejected from the analysis of the linear regression. Some of the diagrams contain a triangle mark connected with line to a circle. This shows the partial TRM (pTRM) test (CoE, 1967b) which is used to detect the change of magnetic properties of a sample during heating. The pTRM induced in a sample at temperature $T_{1}$ after a field-off step at temperature $T_{2}\left(T_{1}<T_{2}\right)$ is compared to the pTRM induced by the field-on step at temperature $T_{1}$.

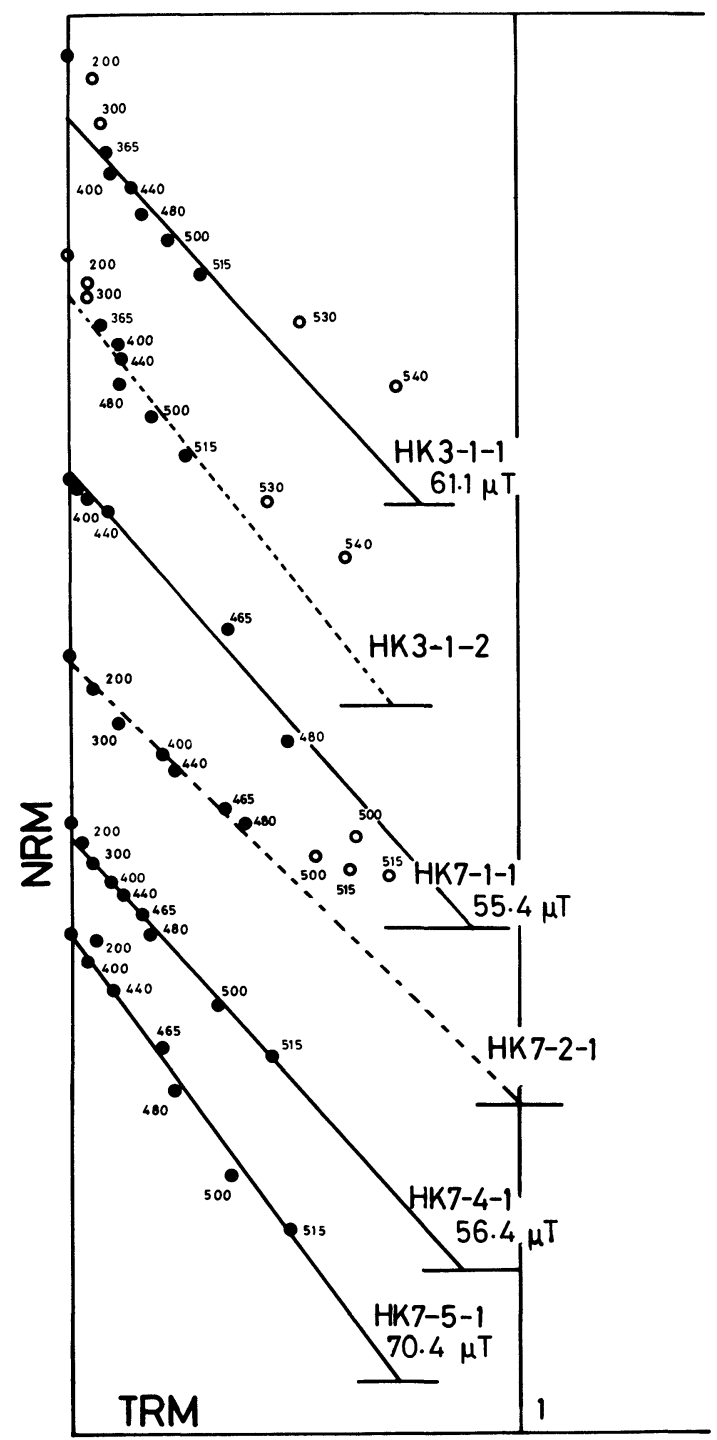

Fig. 2. Arai diagrams for samples of the Oowakudani pyroclastic flow (HK 7) of about 2,900 years B.P. and the Kanmurigatake lava dome (HK 3) which extruded at the same time. In the successive diagrams open circles represent points which were rejected from the analysis of linear regression. A triangle mark connected with line to a circle shows the pTRM test. 


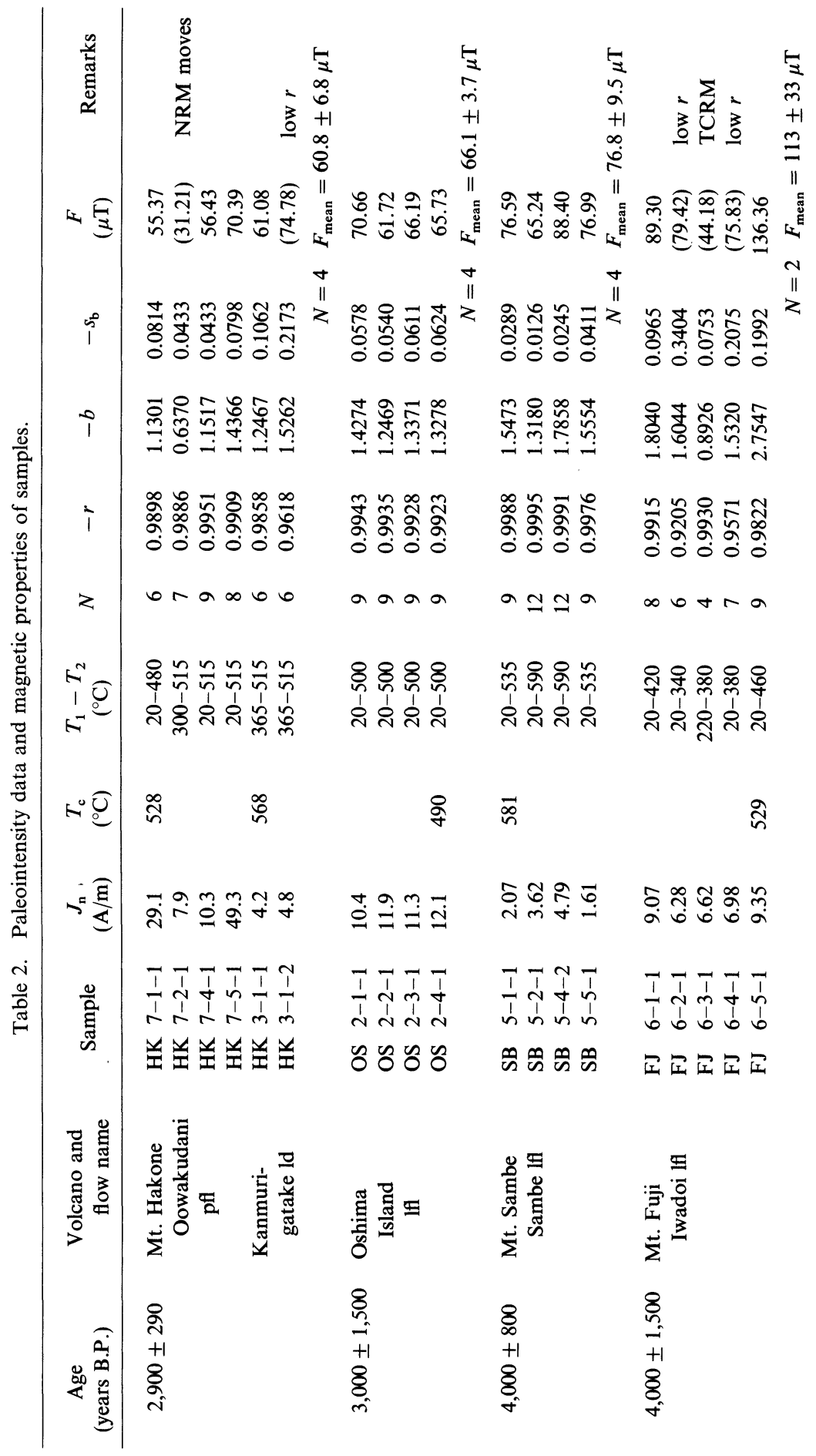




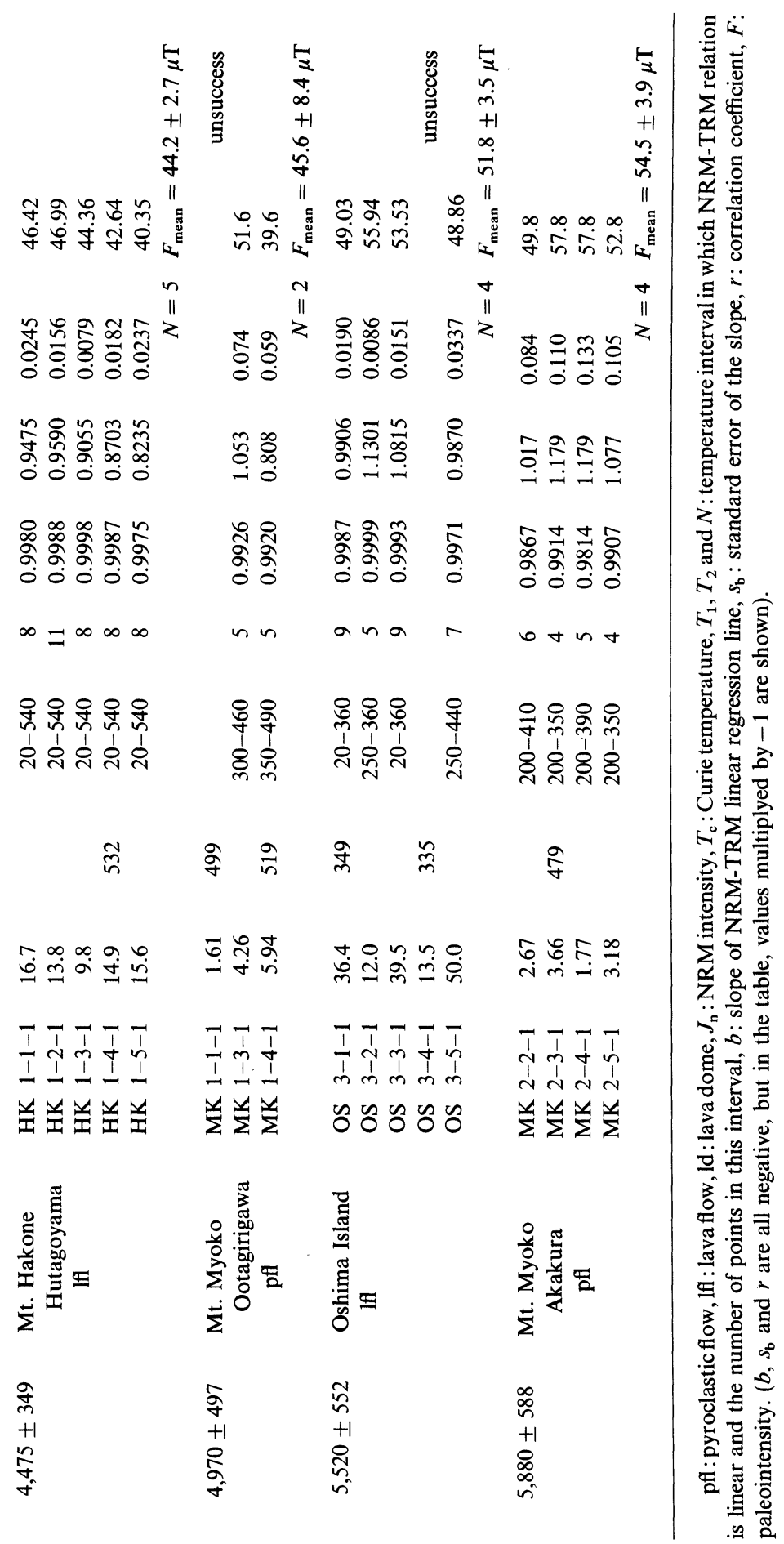




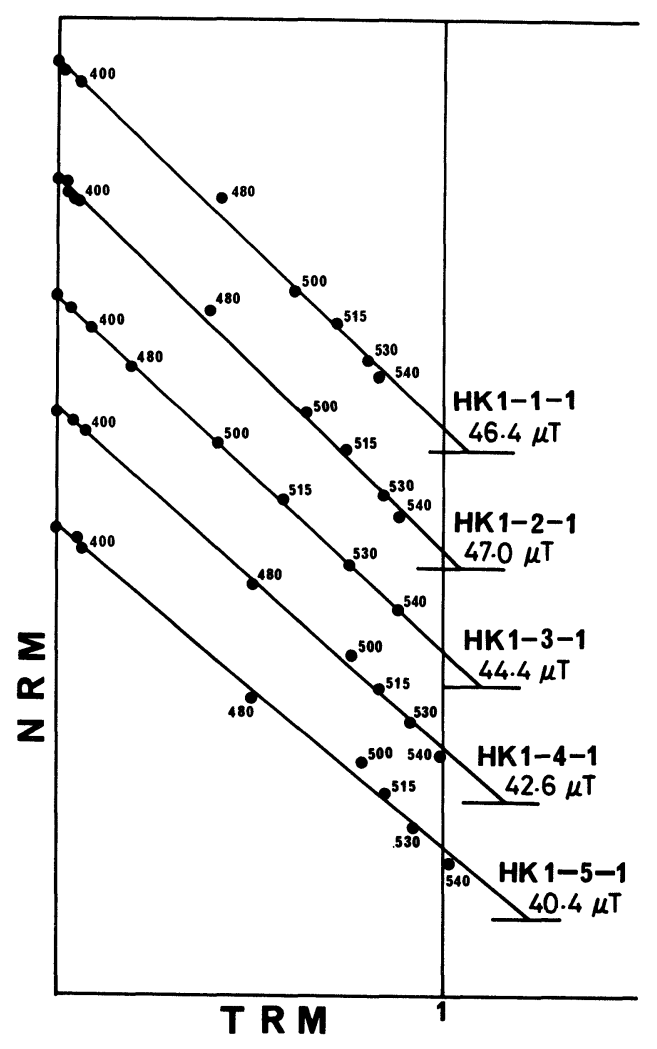

Fig. 3. Arai diagrams for samples of the Futagoyama lava flow (HK 1) of 4,475 years B.P.

Some of the results strongly suggest that the paleointensity experiment should be done with several specimens. An example is the case of Iwadoi lava flow (FJ 6) of about 3,500 years B.P. shown in Fig. 4. Two Arai diagrams of FJ 6-1-1 and FJ 6-5-1 are successful though affected by oxidation of samples at high temperature ranges as known from the pTRM test. The result of FJ 6-3-1 should be treated with a great caution. We may pick up the linear portion between $220^{\circ} \mathrm{C}$ and $420^{\circ} \mathrm{C}$ to obtain the paleointensity. But this is not true because an accidental deviation of the $220^{\circ} \mathrm{C}$ point from the trend of lower temperature ranges caused the apparent linear line of the data of intermediate temperature range. The results of pTRM test show that the Arai diagram of FJ 6-3-1 consists of a linear part of NRM-TRM relation at lower temperature range which should be rejected due to large scatter and apparent linear relation at higher temperatures which might be the effect of thermo-chemical remanent magnetization (TCRM: NAGATA and KoBAYASHI, 1963) caused by oxidation of samples. If we only have the result of FJ 6-3-1 without pTRM test for this lava, we would have made a large error in determination of the paleointensity of the geomagnetic field. This is the reason why in this study the effort was paid to use more than two specimens in the Thellier's experiment. 


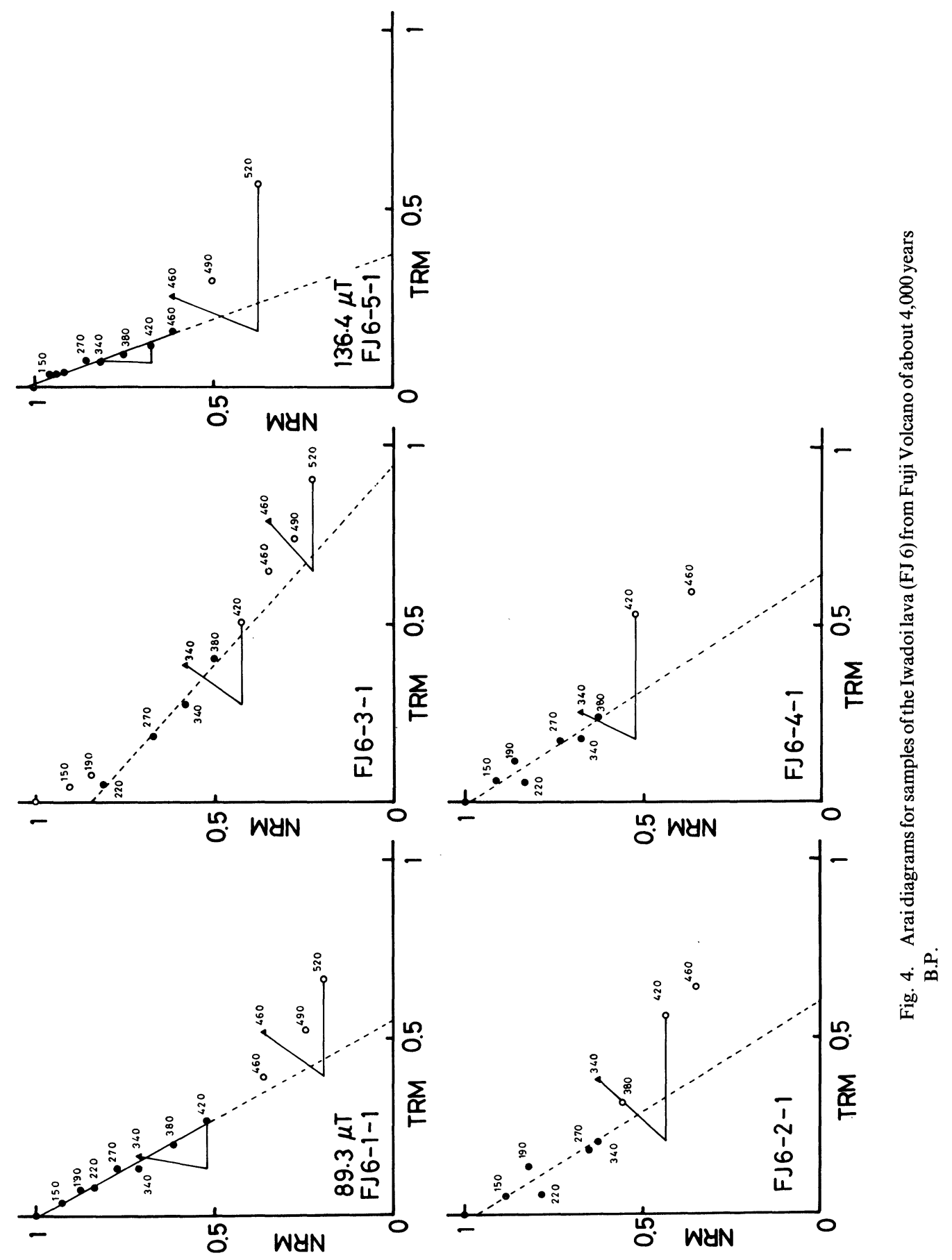




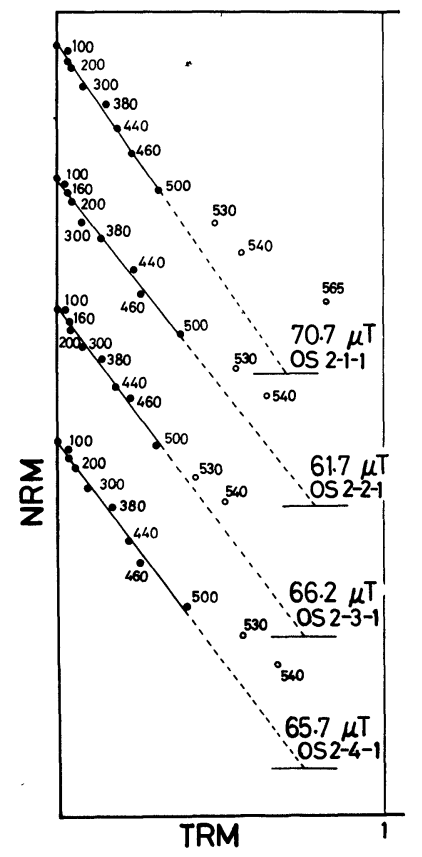

Fig. 5. Arai diagrams for samples of the lava of Oshima Volcano (OS 2) which erupted around 3,000 years B.P.

We should note that the rejected results of the other two specimens (FJ 6-2-1, FJ $6-4-1)$ because of low correlation coefficient have roughly the same trend as those of the successful one. This suggests that we often discard data which are less reliable but still useful. This is also seen in Fig. 2 (HK 3-1-2, HK 7-2-1) and Fig. 7 (MK 1-1-1). We cannot avoid this situation so far as we take the ordinary criteria of accepting or rejecting the result. A new method proposed by CoE et al. (1978) calculate the average paleointensity value by putting weight according to the reliability of each result, so that this method can save less reliable results.

Figure 6 is another example showing the low reliability of Thellier's experiment using a single specimen. The NRM-TRM relation of specimen OS 3-4-1 seems to consist of a linear segment with a large scatter at temperatures below $360^{\circ} \mathrm{C}$ and another linear segment at higher temperatures, but the latter NRM-TRM relation has no significance because the Curie temperature of the magnetic mineral of this specimen is $335^{\circ} \mathrm{C}$ and the linear trend of high temperature range may be due to the production of TCRM. In fact, the slope of the latter linear trend differs from those of successful specimens. We would have calculated a paleointensity from the high temperature linear trend if we got only this result without any knowledge of the Curie point of this specimen. 


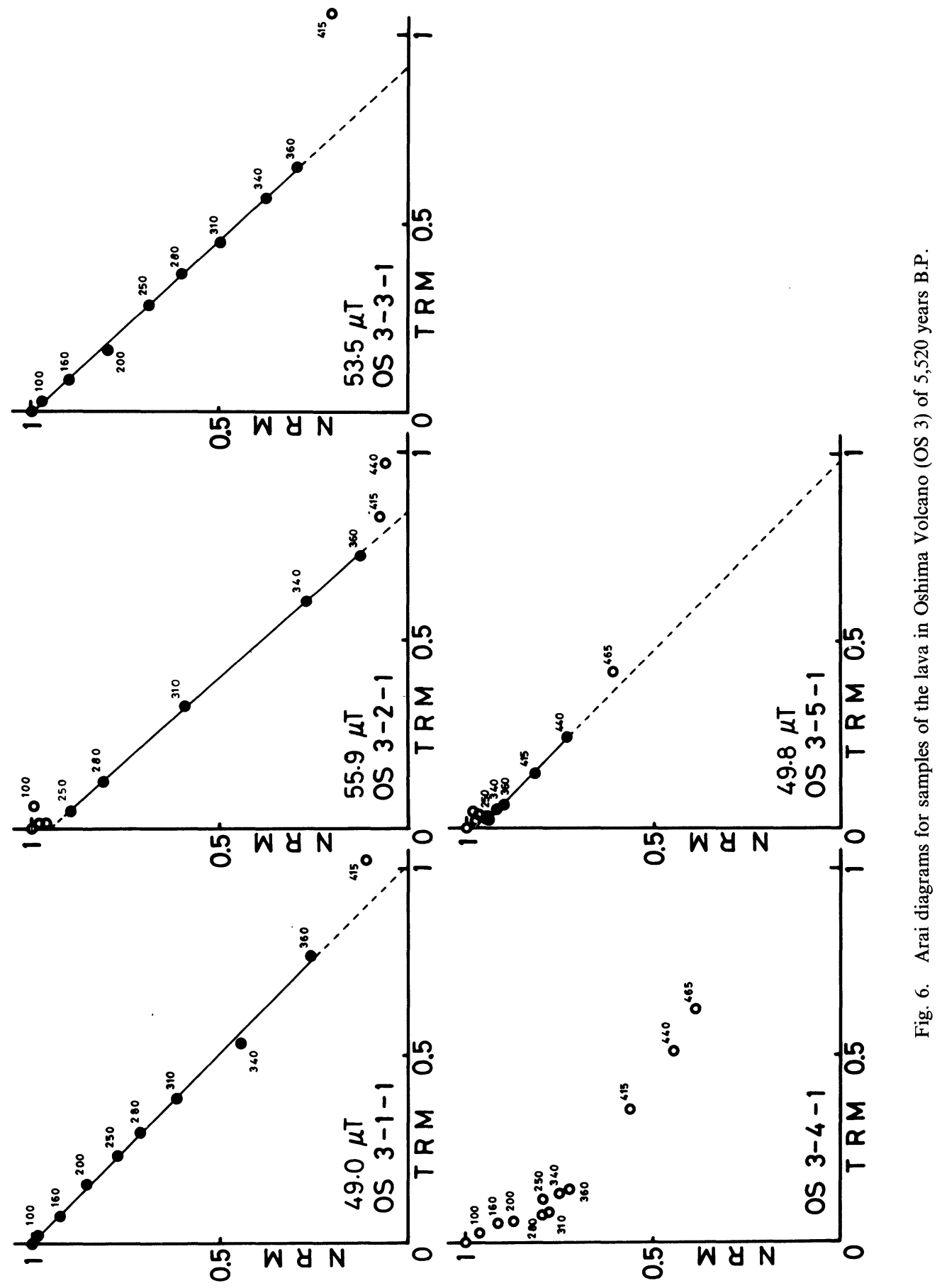



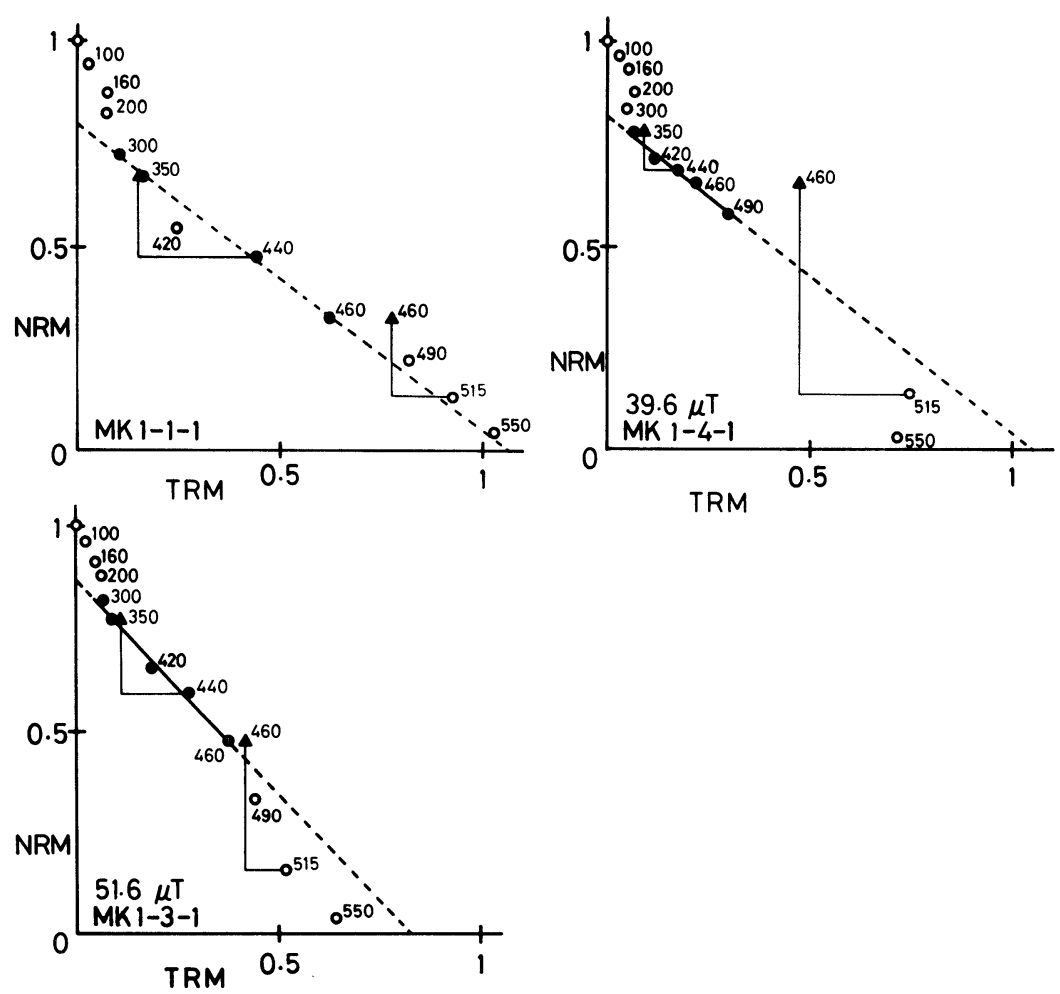

Fig. 7. Arai diagrams for samples of Ootagirigawa pyroclastic flow of 4,970 years B.P.

\section{Discussion}

The eight new paleointensity data obtained in the present study are shown in Fig. 10 together with other data in Japan for the last 6,000 years. We usually compare paleointensity data by converting them to virtual dipole moments (VDM) when the inclination data are known or reduced dipole moments (RDM) when they are unknown. In this study, however, the paleointensity data themselves are shown because of small difference in latitudes of the sampling locations.

For the last 2,000 years, Japanese data well agree with one another if the error of about $10 \mu \mathrm{T}$ is allowed. Many authors have attempted to estimate extent of various errors contained in the paleointensity data. Error of about 15 percent due to non-dipole field is deduced from the present-day geomagnetic field over the whole surface of the earth (SMITH, 1967), and experimental error is usually considered to be about $10 \%$. Local geomagnetic anomaly also causes error of paleointensity data. But the total error of about $10 \mu \mathrm{T}$ (about $20 \%$ ) is still large even when the effect of nondipole field which should be small in Japanese data because of the proximity of the sampling locations, experimental error, and local geomagnetic anomaly are taken into account. It is reasonable to consider that the 

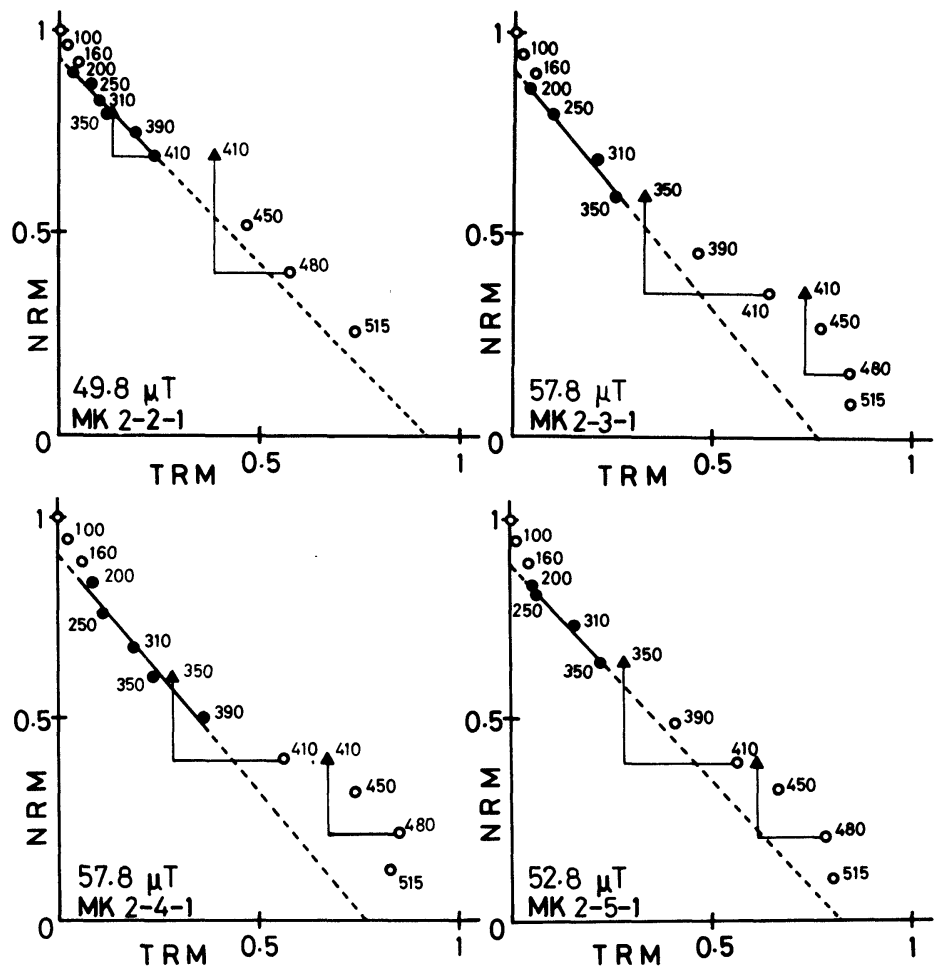

Fig. 8. Arai diagrams for samples of Akakura pyroclastic flow of 5,880 years B.P.

remainder of the total error is caused by the dating error.

BARTON et al. (1979) attributed the scatter of intensity data mainly to the real variation and not to dating uncertainties. However, the dating errors are larger than that usually considered and it is reasonable to assume them at least to be about 10 percent of the age value. NAGATA et al. (1963) attributed their small intensity value around 1,000 years B.P. to the effect of non-dipole field. However, these data are agreeable with other data in Japan if the error of 300 years is assumed in the age determiantion. This suggests great possibility that difference in the intensity value from the other data is caused by error in age determiantion. If so, we can conclude that there was a gradual decrease of geomagnetic field intensity in Japan for the last 2,000 years.

Japanese data for the last 2,000 years, including the recent addition of a large number of data by SAKAI (1980), seem to suggest existence of intensity variation of such a short period as 1,000 years superposed on the gradual decrease. SASAJIMA and MAENAKA (1966) suggested that the dipole wobble model by KaWAI et al. (1965) coincides well with the time variation of the Japanese intensity data. This idea is very interesting but the number of data used by them was too small to make a definite conclusion. From now on, we may be able to analyze the intensity data together with the directional data as Kovacheva (1980) did, since we have now enough number of intensity data as well as the reliable directional data such as HirooKa (1971). 


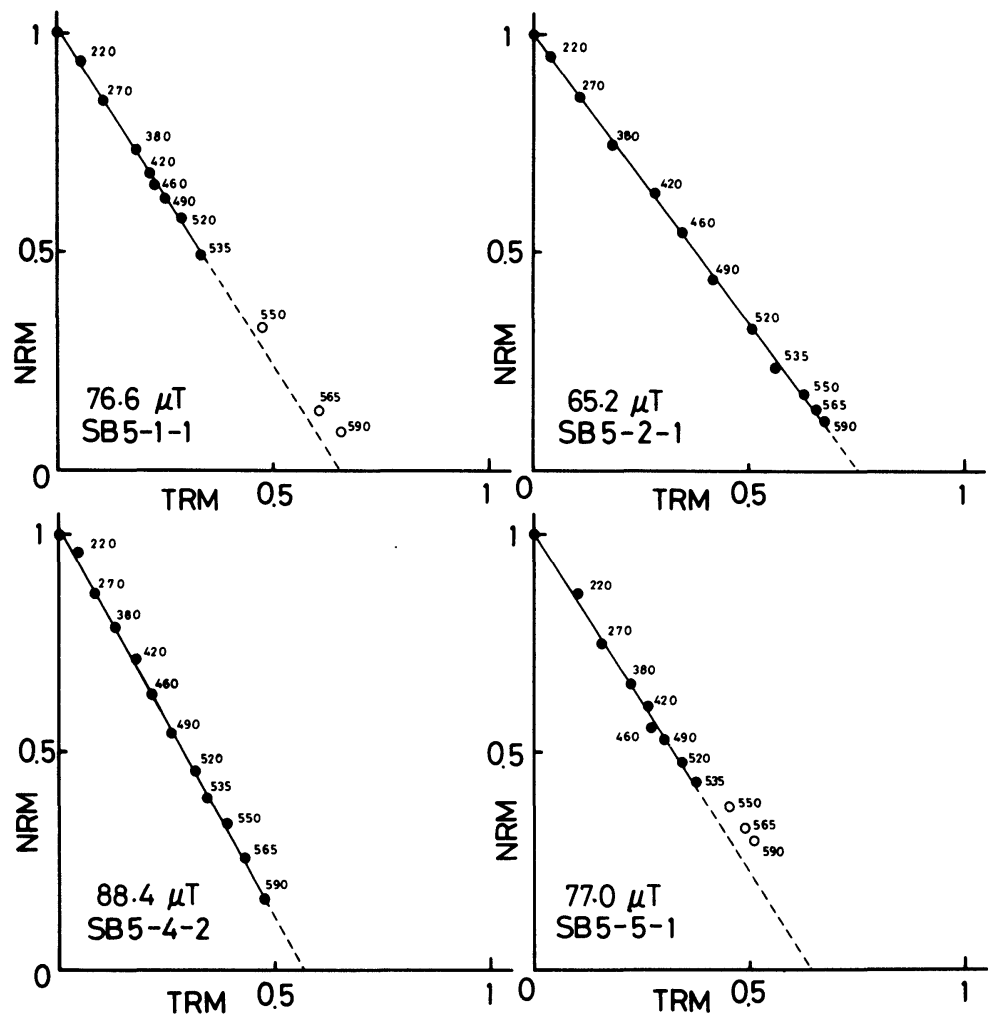

Fig. 9. Arai diagrams for samples of Sambe lava flow (SB 5) taken from Sambe Volcano of about 4,000 years B.P.

KitaZAWA (1970) first studied the intensity variation back to 9,300 years B.P. using potteries recovered from archeological sites. Some of his data show large differences for the same age, but he treated them independently without averaging. So that his curve of geomagnetic field intensity variation shows a large scatter. In Fig. 10 Kitazawa's data are plotted after averaging them when more than one data exist for the same age.

In the period between 4,000 and 2,000 years B.P., data by NaGATA et al. (1963), SaSAJima (1965), KitaZAWa (1970), and SAKaI (1980) as well as the present study agree with one another except one at 4,000 years B.P., showing a gradual increase of geomagnetic field intensity. In the paleointensity variation curve such as Fig. 10, the data of older periods have much larger uncertainty in abscissa rather than ordiante. Though the scatter of data is large, Figure 10 suggests a geomagnetic field intensity of about $40 \mu \mathrm{T}$ around 5,000 years B.P. We can also infer from Fig. 10 that the geomagnetic field intensity gradually increased in this period and there seems to be another minimum around 3,500 years B.P., though many more reliable data are needed to confirm the latter conclusion.

Sinusoidal variation of geomagnetic field intensity was often proposed as a main feature of geomagnetic field (Cox, 1969; BuCHA, 1970). KitAZAWA (1970) also discussed 


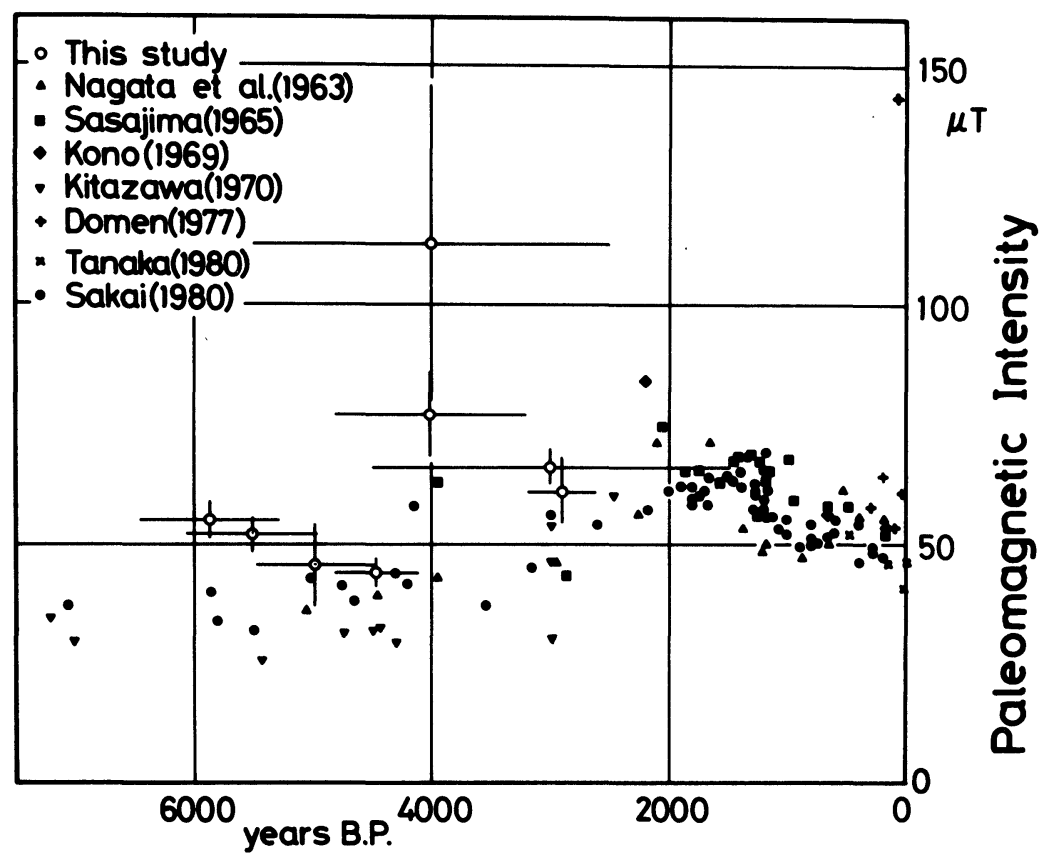

Age

Fig. 10. Paleointensity data in Japan for the last 7,000 years. Error bars were attached only to the data determined in this study.

the sinusoidal variation by comparing the time variation of $\mathrm{C}^{14}$ concentration known from tree rings with theoretical one based on the proposed variation of the geomagnetic field intensity. The sinusoidal variation may be true as a first approximation, though BARTON $e t$ al. (1979) regarded it as highly tentative. The real history of the geomagnetic field may be more complicated. Recently, CoE et al. (1978) found that the intensity variation at Hawaii is quite different from the other data in the world.

\section{Conclusions}

This study provides eight paleointensity data for the period between 6,000 and 3,000 years B.P. Experimental results indicate that the Thellier's experiment using only one specimen sometimes gives a paleointensity of low reliability because of misinterpretation of the Arai diagram which contains an apparent linear NRM-TRM relation probably caused by the production of TCRM. It was strongly recommended to carry out the Thellier's experiment by using several at least three, specimens.

We should pay attention not only to the error in the intensity value but also to that in the age of the sample. Japanese data for the last 2,000 years agree well when the error of $10 \mu \mathrm{T}$ is allowed in intensity and 10 percent of the error of age data is also taken into consideration. Japanese paleointensity data for the last 6,000 years including the results of 
this study are in favor of the already proposed interpretation that the geomagnetic field intensity gradually increased from 6,000 to 2,000 years B.P. and then decreased to the present-day value. The secular variation with shorter periods seem to exist superposed on the gradual variation not only during the last 2,000 years but also in the periods older than 2,000 years B.P.

I would like to express my sincere gratitude to Prof. M. Kono of Tokyo Institute of Technology for the continuing encouragement and many discussions throughout this study. I also thank him for his kindness to read the manuscript and to suggest possible improvements. I am indebted to Prof. T. Rikitake of Nihon University, Dr. Y. Honkura of Tokyo Institute of Technology, Prof. M. Ozima and Prof. T. Yukutake of University of Tokyo for encouragement and helpful suggestions. I wish to thank Prof. H. Machida of Tokyo Metropolitan University for valuable suggestions about the selection of dated volcanic ejecta and also for the help in sample collection at Fuji and Hakone Volcanoes. I also thank the following geologists for the information and help in sample collection: Dr. K. Hayatsu of Arai City for Myoko Volcano, Dr. N. Isshiki of the Geological Survey of Japan and Prof. K. Nakamura of University of Tokyo for Oshima Volcano, and Dr. S. Matsui of Education Center of Shimane Prefecture for Sambe Volcano. Many other persons also helped in sampling: Drs. Y. Hamano and T. Tosha of University of Tokyo, Dr. K. Kodama of Kochi University, Dr. T. Nishitani of Akita University, Dr. M. Joshima of Geological Survey of Japan, Prof. M. Kono and Dr. N. Oshiman of Tokyo Institute of Technology. Measurements of remanences in this study were done at University of Tokyo and the Geological Survey of Japan. For the use of the spinner magnetometer I am grateful to Prof. M. Ozima and Dr. Y. Hamano of University of Tokyo and also to Dr. M. Joshima, Dr. M. Ono, Dr. H. Murakami and Dr. I. Sato of the Geological Survey. Partial financial supports by the Ministry of Education (Grant No. 374116, 56740156) and by Ito Science Foundation are gratefully acknowledged.

\section{REFERENCES}

ARAI, Y., Secular variation in the intensity of the past geomagnetic field, M. Sc. thesis, pp. 84, Univ. of Tokyo, Tokyo, Japan, 1963.

BARTON, C. E., R. T. MERrill, and M. BARBETti, Intensity of the earth's magnetic field over the last 10000 years, Phy. Earth Planet. Inter., 20, 96-110, 1979.

Bucha, V., Evidence for changes in the Earth's magnetic field intensity, Phil. Trans. R. Soc. Lond. A, 269, 47-55, 1970.

Burlatskaya, S. P. and I. E. NaChasova (compilers), Archaeomagnetic determinations of geomagnetic field elements, in Materials of the World Data Center B, 112 pp., Sov. Geophys. Comm. Acad. Sci. U.S.S.R., Moscow, 1977.

CoE, R. S., Paleo-intensities of the earth's magnetic field determined from Tertiary and Quaternary rocks, $J$. Geophys. Res., 72, 3247-3262, 1967a.

CoE, R. S., The determination of paleo-intensities of the earth's magnetic field with emphasis on mechanisms which could cause non-ideal behavior in Thellier's method, J. Geomag. Geoelectr., 19, 157-179, $1967 \mathrm{~b}$.

CoE, R. S., S. Gromme, and E. A. MANKInEN, Geomagnetic paleointensities from radiocarbon dated lava flows on Hawaii and the question of the Pacific nondipole low, J. Geophys. Res., 83, 1740-1756, 1978.

Cox, A., Geomagnetic reversals, Science, 163, 237-245, 1969.

DOMEN, H., A single heating method of paleomagnetic field intensity determination applied to old roof tiles and rocks, Phys. Earth Planet. Inter., 13, 315-318, 1977.

Hayatsu, K., The last activity and eruptives of the Myoko volcano-Geologic descriptions of the Myoko volcanoes (1), The Quat. Res., 14, 1-13, 1975 (in Japanese).

HaYatsu, K. and N. Furukawa, ${ }^{14} \mathrm{C}$ age of the Akakura pyroclastic flow and the Taguchi mud flow deposits from Myoko volcano, central Japan, The Quat. Res., 20, 31-33, 1981.

HirooKA, K., Archaeomagnetic study for the past 2,000 years in Southwest Japan, Memo. Fac. Sci. Kyoto Univ., Ser. Geol. Mineral., 38, 167-207, 1971.

Isshiki, N., K. NAKAMURA, and K. TAZAWA, Average interval of major activities of Oshima Volcano, Izu, as revealed by ${ }^{14} \mathrm{C}$ dating, Bull. Volcanol. Soc. Japan, 26, 235-238; 1981 (in Japanese). 
Kawai, N., K. Hirooka, S. Sasajima, K. Yaskawa, H. Ito, and S. Kume, Archaeomagnetic studies in southwestern Japan, Anns. Geophys., 21, 574-578, 1965.

KIGOSHI, K., Errors in radiocarbon age determination and correction of radiocarbon dates, Quat. Res., 6, 151-157, 1967 (in Japanese).

Kitazawa, K., Intensity of the geomagnetic field in Japan for the past 10,000 years, J. Geophys. Res., 75, 7403-7411, 1970.

Kono, M., Intensity of the earth's magnetic field in Pliocene and Pleistocene, D. Sc. thesis, 58 pp., Univ. of Tokyo, Tokyo, Japan, 1969.

Kono, M., Mathematical models of the earth's magnetic field, Phys. Earth Planet. Inter., 5, 140-150, 1972.

Kono, M., Reliability of palaeointensity methods using alternating field demagnetization and anhysteretic remanence, Geophys. J. R. Astr. Soc., 54, 241-261, 1978.

Kovacheva, M., Summarized results of the archaeomagnetic investigation of the geomagnetic field variation for the last $8000 \mathrm{yr}$ in southeastern Europe, Geophys. J. R. Astr. Soc., 61, 57-64, 1980.

MACHIDA, H., Tephrochronological study of Volcano Fuji and adjacent areas, (1) and (2), J. Geogr., 73, 293-308, 337-350, 1964 (in Japanese).

MACHIDA, H., Stratigraphy and chronology of late Quaternary marker-tephras in Japan, Geographi. Rep. Tokyo Metrop. Univ., 11, 109-132, 1976.

MaChida, H., Kazanbai wa kataru (What Tephra Tells), 324 pp., Soju, Tokyo, 1977 (in Japanese).

MAtsui, S. and T. Inoue, ${ }^{14} \mathrm{C}$ ages of pyroclastics from Volc. Sambe, Earth Sci. (Chikyu Kagaku), 24, 112-114, 1970 (in Japanese).

Nagata, T., Y. ARAI, and K. Momose, Secular variation of the geomagnetic total force during the last 5000 years, J. Geophys. Res., 68, 5277-5281, 1963.

NagAta, T. and K. Kobayashi, Thermo-chemical remanent magnetization, Nature, 197, 476-477, 1963.

NaKamURA, K., Volcano-stratigraphic study of Oshima Volcano, Izu, Bull. Earthq. Res. Inst., Univ. Tokyo, 42, 649-728, 1964.

SAKAI, H., Variation of geomagnetic field deduced from analysis of remanent magnetization of archeological objects, D. Sc. thesis, 95 pp., Osaka Univ., Osaka, Japan, 1980.

SASAJIMA, S., Geomagnetic secular variation revealed in the baked earths in West Japan (Part 2) Change of the field intensity, J. Geomag. Geoelectr., 17, 413-416, 1965.

Sasajima, S. and K. MaEnaKa, Intensity studies of the archaeo-secular variation in West Japan, with special reference to the hypothesis of the dipole axis rotation, Mem. Coll. Sci., Univ. Kyoto, Ser. B., 33, 53-67, 1966.

SHAw, J., A new method of determining the magnitude of the paleomagnetic field, application to five historic lavas and five archaeological samples, Geophys. J. R. Astr. Soc., 39, 133-141, 1974.

SмIтH, P. J., The intensity of the ancient geomagnetic field: A review and analysis, Geophys. J. R. Astr. Soc., 12, 321-362, 1967.

TANAKA, H., Paleointensities of the geomagnetic field determined from recent four lava flows of Sakurajima Volcano, J. Geomag. Geoelectr., 32, 171-179, 1980.

TAzAWA, K., Activity of Izu-Oshima volcano during 10,000 years prior to the caldera formation: a volcanostratigraphic approach, Bull. Volc. Soc. Japan, 25, 137-170, 1980 (in Japanese).

TAZAWA, K., ${ }^{14} \mathrm{C}$ ages of Izu Oshima Volcano and a revised estimate of the average interval of volcanic activities, Bull. Volc. Soc. Japan, 26, 69-70, 1981 (in Japanese).

Thellier, E. and O. Thellier, Sur 1'intensite du champ magnetique terrestre dans le passe historique et geologique, Ann. Geophys., 15, 285-376, 1959. 